\title{
NEVER TO ME! \\ CONCEALMENT OF INTIMATE PARTNER VIOLENCE IN QUERÉTARO, MEXICO
}

\author{
M. E. Meza-de-Luna ${ }^{1}$, M. L. Cantera-Espinosa ${ }^{2}$, P. Westendarp-Palacios ${ }^{1}$, \\ P. Palacios-Sierra ${ }^{1}$ \\ ${ }^{1}$ Universidad Autónoma de Querétaro, Querétaro, México, \\ and ${ }^{2}$ Universidad Autónoma de Barcelona, Spain
}

\begin{abstract}
The study examines the concealment of intimate partner violence (IPV) involving men and women of different sexual orientation in Querétaro, Mexico. Grounded Theory was used to analyze both semi-structured interviews (for $n=43$ ) and photointerventions (for $\mathrm{n}=18$ ). One of the main factors associated with the concealment of IPV is gender stereotype, which in turn influences the application of justice and the beliefs grounded in idyllic love. Other factors include youth, social stigmatization of violence, fear of loss of relationships, damaging effects on children, and social isolation. The findings reveal that IPV concealment is a common practice among men and women of different sexual orientation. Hence, increased efforts in the development of an inclusive public policy to address these problems should be undertaken.
\end{abstract}

Keywords: intimate partner violence, concealment, gay, lesbian, bisexual, heterosexual, Mexico

DOI: $10.3176 /$ tr.2015.2.04

\section{Introduction}

Intimate partner violence (IPV) is a public health problem. Its prevalence is greater than that of other serious health problems (e.g. breast cancer) that have received wide coverage and financing because of wide-spread awareness (Logan et al. 2006). For example, in most Western nations one in four women are at risk for IPV. In Mexico, it is estimated that the preponderance of IPV in women is psychological (37.7\%), physical (23.4\%), and sexual (9.5\%) (Ortega-Ceballos et al. 2007) and that at least $40 \%$ of pregnant women suffer IPV (Sánchez-Jimenez, et al. 2008). 
One of the great struggles of the past four decades has been publicizing the high prevalence and the impact of the IPV. In addition, recognizing and encouraging formal and informal complaints of IPV pose significant challenges. IPV concealment reduces the public awareness of its actual occurrence, resulting in less attention by public policy. It is also known that reports to the court system usually result in two phenomena: (1) a decrease in violence between the couple (Willson et al. 2001) and (2) people subjected to aggression feel safer and better about themselves (Malecha et al. 2003, Logan et al. 2006). So, understanding the obstacles that limit complaints, whether formal or informal, can have an impact for both an individual and the society.

Seeking help or registering complaints has been studied mainly regarding women. However, there is a lack of empirical studies to improve the understanding of the reasons why women tend to hide their IPV (Leone et al. 2007). Moreover, there is a lack of a broad understanding of the phenomenon that includes men and women of different sexual orientation. Our study specifically addresses this problem. Our objective is to better understand the IPV concealment by women and men in heterosexual, gay, lesbian, and bisexual populations (HGLB) in Querétaro, Mexico. In this paper, we address the question: How do people explain their practice of IPV concealment?

\subsection{Research context}

Querétaro is a state located in the central highlands of the Mexican Republic, two hundred miles northwest of Mexico City. It is distinguished by its small size $\left(11,269 \mathrm{~km}^{2}\right)$, and rapid industrial modernization that began in the 1960s. As a consequence Queretaro is a state that is located in the central highlands of the Mexican Republic, two hundred miles northwest of Mexico City. It is distinguished by the disruption of the economic structure of Querétaro, resulting in industrial development with the concomitant decline in agriculture. This phenomenon has led to a significant population growth, through both natural increase and immigration. Currently, the population is 1,827,937 inhabitants (Instituto Nacional de Estadística y Geografía 2013), of which 51.46\% are female and $48.53 \%$ are male. In addition, young people predominate: $29.81 \%$ are between 0 and 14 years of age and $27.84 \%$ are 15 to 29 years of age. In contrast, $21.76 \%$ are between 30 and 44 years of age, and 19.85\% are between 45 and 65 years of age.

Another important consequence of industrialization in Querétaro is the diversification of its labor market, in which wages from labor increased as did the presence of women in the work force (Palacios-Sierra 2007). Working women in 2007 were $41.4 \%$ of the work force compared to 38.2\% in 2000 (Instituto Nacional de Estadística y Geografía 2008:17). These factors, among others, influenced the greater heterogeneity of households today, as reflected in these statistics: $72.9 \%$ are nuclear households (as defined by United Nations n.d.), $18.8 \%$ are extended households, $6.5 \%$ are one-person households, $0.6 \%$ are coresident households, and $0.5 \%$ are composite households. Also, households 
headed by women have increased from $19.8 \%$ in 2000 to $22 \%$ in 2005 (Instituto Nacional de Estadística y Geografía 2008:3).

Despite these changes, which have probably contributed to making Querétaro one of the five safest states in the country (Calzada-Rovirosa 2012) in terms of relationships between men and women, significant inequalities remain. According to the Gender-related Development Index, Querétaro ranks 13th of 31 states in Mexico, with large differences in education, economic conditions, health, and decision-making roles, both in public and in private environments (Instituto Nacional de Estadística y Geografía 2008:4-5).

To the above summary, violence perpetrated against women should be added. In Querétaro, the Women Institute of Querétaro (Instituto Municipal de Equidad y Género 2008) found that $38.1 \%$ of women had suffered violent acts in public and private spaces throughout their lives; $37.6 \%$ of employed women were subject to discriminatory practices such as lack of recognition at work, impeding opportunities for advancement, and abuse; $36.7 \%$ suffered some violent incident by their partner during their relationship; $17 \%$ were assaulted or abused by an immediate relative or another relative such as an in-law or a godparent; $16.6 \%$ of the female population suffered violence during their student life, inflicted by a colleague, teacher, or someone among the school administration; and 6\% were robbed by a relative or an unrelated co-resident person. In intimate relationships, the predominant violence was psychological, followed by physical, economic, and sexual (Facultad de Ciencias Políticas y Sociales 2012:8, 11). This information illustrates the importance of analyzing and understanding the extent of these problems in the economically vibrant state of Querétaro today, and is the subject of this report.

\section{Review of the literature}

Previous studies illustrate the reasons why battered women as part of a couple are deterred from pursuing a court order for protection. Malecha et al. (2003) found that the reasons women decline the judicial process is because they have reconciled with their partner $(40.5 \%)$, the process was tiring and inconvenient $(23.8 \%)$, or they wish to protect their children and/or the abuser (19.0\%). Other reasons may be that they no longer needed the order (e.g. because they were initiating a divorce and the abusing husband was in prison, $14.3 \%$ ), or the couple's lawyer persuaded them not to seek legal protection (2.4\%). While these results are not about the concealment of IPV, they indicate a withdrawal of women from legal action already undertaken, and provide a basis to begin to understand the reasons that might be associated with IPV concealment.

The complaint act is a process of seeking help where the traumatized person begins to look out for his or her well-being, an important part of overall wellbeing, health, and psychological recovery of an abused person. When a person experiencing IPV receives counseling, there is generally a significant decrease in 
the depressive symptoms that are normally associated with abuse (Coker et al. 2012). However, most IPV cases are unreported (Melton and Sillito 2012). For example in Mexico, $77.07 \%$ of the physical and/or sexual IPV suffered by women is not reported to statutory agencies (Frías 2013). Studies have indicated that factors that inhibit the complaints of women include their own childhood development in an environment of violence (Burgess-Proctor 2012, Frías 2013) and that seeking formal help (e.g. from legal, health, or social agencies) is lower when the IPV is situational (Leone, Johnson, and Cohan 2007), which is linked to the conflict (Johnson, 1995), and that informal complaints (e.g. to relatives, friends, and neighbors) is lower when these systems are perceived as inadequate (Meyer 2010).

IPV has a certain degree of tolerance. Agoff et al. (2006) conducted a study in Mexico on the tolerance of IPV in a sample of battered women. Their results show that the reasons for abuse offered by victims are very important in order to understand the justification and attribution of responsibility for the violence, as well as the threshold of tolerance of the victims. They found that women who explain male violence as an impulsive act of frustration, without intent to harm, are offered by women who are accustomed to tolerating high levels of violence. By contrast, women tend to tolerate less violence and blame the man, when they interpret abuse as "punishment" for not meeting the expectations of their gender. The findings of Agoff et al. (2006) suggest some variables to consider in the study of concealment of IPV by women, although further studies that include men and women of different sexual orientation are needed.

In the early eighties, there was greater academic, public, and political attention devoted to the study of physical violence by men on women. Today, however, women's violence is increasingly being studied in their various relationships (Thornton et al. 2012, Melton and Sillito 2012). IPV is starting to be seen more as a human problem than as a gender problem (Hamel 2007), and thus multi-causal and systemic factors that affect IPV are now considered. In this sense, Straus (2006) proclaims that studies of couples should not focus solely on the responses of women but should include responses of men as well. Herein, we present a study of IPV concealment that includes the behavior of men and women of different sexual orientation (HGLB), with the intention of improving the understanding of this phenomenon in the Mexican population.

\section{Method}

This research was conducted from an interpretive perspective. It focuses on the way people see the world where their perceptions do not necessarily have permanent nature. It is assumed that the social world exists in a state of fluid interaction, and that this must be at least partially understood (Oliver 2008). This research methodology looked for the meanings, norms, and values that people 
have given to their practices of IPV concealment. The study was part of an international research project that included seven countries. ${ }^{1}$

\subsection{Sampling and participants}

We performed sampling by theoretical saturation, in which the sample is subject to the development of emerging theory. At different times of the research process, we looked for participants with specific characteristics or experiences that helped to explore more deeply the purposes of the study (Strauss and Corbin 2002). The inclusion criteria for sample selection required participants to be at least 18 years of age, Mexican, to have had an intimate relationship (dating, cohabitation, or marriage), and to reside in urban Querétaro.

The sample consisted of 61 people, ranging from 18 to 69 years $(M=37.5$, $\mathrm{SD}=12.6$ years), $52.5 \%$ were women, $21.3 \%$ had a same-sex partner experience, $80.6 \%$ had a relationship of more than one year, $68 \%$ had a partner at the moment of participation, and $41.6 \%$ had one or more children. The marital status of these participants was: $42 \%$ unmarried, $31 \%$, married, $14 \%$ divorced, $8 \%$ separated, and $6 \%$ cohabited with a partner. The majority $(80.6 \%)$ had a high school education.

\subsection{Procedure and instruments}

We described the study to key representatives from educational institutions (e.g. universities, sex education centers, and sports institutions. Depending on the particular procedures of each institution, we were allowed either to directly invite the entire community or institution to distribute information about the study and to provide our contact information. To alleviate concerns about these studies, possible participants attended a meeting or received telephone calls in which the general procedures of this study were described in order to resolve doubts, to answer questions, and to agree upon the times and locations of future sessions.

Interviews and photo-interventions (Cantera-Espinosa, 2009) were used to gather data. Semi-structured interviews $(n=43)$ addressed the topics of this broad study, which explores the beginning of the relationship, conflict arousal and management, motivations to stay or leave the relationship, and available support networks for difficult situations.

Photo-intervention $(\mathrm{n}=18)$ is a technique to facilitate the incursion into sensible problems, based on the use of photography from the sociological (Sontag 2005) and clinical (Sanz 2008) areas. We provided disposable cameras to participants to photograph their conflicts. At the session that followed one week later, the participants discussed their photos freely. This was followed by a discussion of convergent themes that emerged among participants, in which the investigator explored topics related to the themes arising from the discussion. Afterwards, using the images captured by members of the group, approximately 10 photographs were selected to

1 "Violencia de género. Nuevos desafios para la investigación y la intervención" (Gender violence. New challenges for research and intervention). Plan I+D+I 2004-2007, MAS - Instituto de la Mujer. Referencia: Exp. 13/05. 
summarize the conflicts, violence, and consequences of this relationship. Finally, there was a discussion that focused on the values, cultural perceptions, and structural issues of the conflict and violence. Interviews and photo-interventions of 45 to 250 minutes (the average length of 130 minutes for these interviews) were recorded digitally. Photo-interventions and interviews were transcribed verbatim in Spanish, and an English translation of the quotations is included here.

\subsection{Analysis, credibility, and reliability}

We used Grounded Theory (Charmaz 2008, Strauss and Corbin 2002) to analyze the data, which consists of a recursive and simultaneous process of collecting, codifying, and analyzing data. We followed the constant comparison procedure to achieve density of properties and dimensions for each category. Atlas.Ti software (2007) was used for qualitative analysis.

The credibility and reliability in the research process is supported by the complete textual transcripts of the interviews and by including different groups of people with a variety of: (1) experiences in relationships between couples, such as dating, cohabiting, married, divorced, or separated; (2) sexual orientation; (3) age; (4) degree of perceived aggression, including a range of physical abuse, from none or little physical abuse to death threats. Also, as much as possible, we performed communicative validation (Mendizábal 2006) in which the participants evaluated the summaries of the interviews. Triangulation was carried out using two different techniques at different times and stages, in which the first stage used interviews and the second stage used photo-intervention. The initial findings were judged by a group of four experts within the clinical and the social psychology areas. These experts confirmed that the results clarified aspects of the phenomenon of IPV concealment.

\subsection{Ethics of the investigation}

The research followed the ethical guidelines established by the American Psychological Association (APA 2010). Participation was voluntary and always under a protocol of informed consent. We explained to the participants the objectives of the study, how their personal data will be managed to insure their anonymity, that their participation is voluntary without any sanction if they withdrew from the study, and that their permission to record the findings must be given. For photo-intervention, participants filled out a written form of consent that their photographs may be used for academic purposes.

\section{Results}

We determined that IPV concealment has eight different factors: gender stereotypes, normalization of violence and its stereotypes, socio-structural system inefficiency, idyllic love, social stigma of violence, youth, caring for children and relationships, and isolation. These conditions are described below. 


\subsection{Gender stereotypes}

Gender stereotypes promote concealment of IPV. We found a tendency to naturalize $^{2}$ in the feminine figure ${ }^{3}$ : helplessness that implies weakness, passivity, and submissiveness. It is related to the lack of power and agency in IPV, leading to resignation. Concealment of IPV is consistent with these characteristics. In addition, there is the perception that the female figure needs external defense that is usually complemented by the male figure. Hence, IPV concealment reinforces the apparent protection and security that the male figure supplies in other areas of life (e.g. economic livelihood, protection on the street or protection against another person).

On the other hand, the male figure is characterized with: the exercise of power, control over himself and over his partner, the exhibition of self-reliance and capacity in a quasi-omnipotent sense (e.g. economic, intellectual, physical). For men living with IPV to denounce the violence represents their failure to meet the canon imposed upon males. For such men, it is shameful to be weak. The concealment of IPV is a way to safeguard their identities. By pretending that such violence does not happen in their life, they avoid admitting publicly to their inability to dominate. For example, Jose (a 46 year-old gay man) said that men do not report IPV because "if you do not respond to the male canon [of power and control], you would look very bad [...]. Although I am suffering, I will not accept it. I will not say anything, because if I do, I will look bad, I would not be man enough." Hence, for men reporting IPV is a double affront. First, it compromises the male mandate of capacity, power, and control. Second, the reporting of IPV is considered similar to the female stereotype associated with helplessness and lack of self-sufficiency. Thus, an external defense is necessary because it is expected that only women would complain and ask for help. Therefore, IPV concealment is a strategy of self-defense for men. This very act serves to reconstruct, to some extent, their image as male because by concealing IPV men can rebuild part of their capacity of self-sufficiency and control.

\subsection{Normalization of violence and its stereotypes}

Violent acts are so common that they appear to be normal, leading to a trivialization of the phenomenon. People develop a culture of uncritical tolerance that prevents them from recognizing it as aberrant. It seems that there are no mental structures to prevent it. Thus, we found some practices of psychological violence (e.g. control over time spent on activities or on friendships) that are considered insignificant.

2 To assume that certain practices, attitudes and roles are unique to men and some others to women, as if it were intrinsic to nature.

3 It should be noted that we refer to the female figure for men and women of any sexual orientation, who share characteristics regarded as feminine. In the same manner, the male figure refers to people of any sex and sexual orientation, who share characteristics regarded as masculine. 
Additionally, within gender stereotypes, those of violence may be intertwined, e.g. a man's violence may be seen as normal. It is usually considered that men face conflicts aggressively. Thus, male violence is justified, in men and women, as something natural and expected. So, the IPV experienced by heterosexual women is overlooked and accepted by women and by society. It leads to the concealment of IPV as a consequence of a characteristic that cannot be change because it is what it is.

In contrast, because violence is expected to be largely restricted to men, this limits the recognition of the IPV that women can exert. Because women are perceived to be psychologically far from violent, we found in lesbian women a barrier to detect and recognize their own form of IPV. On the other hand, we found that generally for heterosexual men, women's violence is difficult to comprehend. For example, Raul (an unmarried 26 year-old heterosexual man), described as "ridiculous" the possibility of experiencing psychological violence from his girlfriend, when she monitored his friendships, time, and possessions:

Raul: Every time I went out with my friends, my girlfriend was annoyed. She was angry about everything, and for nothing. So, to keep our relationship calm, I started to avoid going out with my friends. The whole time, I was with my girlfriend $[\ldots]$

Interviewer: And now that you're saying this, would you consider that there was violence?

Raul: Perhaps the psychological, but I do not know, it sounds so ridiculous" [then he described how his girlfriend also used to check his cell phone and his email]

Interviewer: And there, did you feel as a victim of violence?

Raul: NO, no [quite emphatic], you do not feel like a victim, you just act more to defend what is yours, but never as a victim.

\subsection{Inefficiency in the application of justice}

We found that negligence and ignorance of the pipeline of the system for complaints are forms of inefficiency in the application of justice that contribute to the silence of IPV. Negligence in the lack of application of the law by the government institutions results in the discredit and distrust of the system. Also, negligence can be derived from IPV minimization, seen as natural or as a private issue (e.g. Paco, a 26 year-old heterosexual man: "In the plaza, there was a man hitting his wife. I asked the police to help, but the officer told me - that is their business; they have to deal with it themselves"). Concealment of IPV sometimes appears as the lack of confidence in the socio-politico-legal system. People prefer to hide IPV when they are doubtful about the effectiveness of intervention to stop the aggression, or even worse, when they fear a more severe subsequent retaliation after complaining. For example, Martha has lived in Mexico and in the United States. She compared her experience of complaining about IPV in both countries, and testified to the effect of concealment derived from discredited Mexican institutions: 
"Here (in Mexico) I never tried to sue my husband. When we were in the U.S. he stopped hitting me, but we came back to Mexico and he started beating me again. I knew that here the police would not give me any attention as they do in USA. Over there, as soon as I called the police, they arrived to help me and they took my husband to court with judge. Here the truth is I'm scared; what if they fail to come or if they do not support me? Then I will be in a worse situation": Martha (a married 46 year-old heterosexual woman).

Furthermore, neglect can be interwoven with gender stereotypes. Although there are public policies intended to alleviate IPV, such as specialized agencies for IPV complaints, they still intersect with gender stereotypes that undermine their effectiveness. We found that people responsible for receiving complaints of IPV respond in such a way that they reinforce gender stereotypes and restrict complaints. Janet (a single 25 year-old lesbian woman and a lawyer):"The Justice system is not working. I have a man client who has been maltreated by his wife. Once he went to the police agency to sue his wife, but he got as a response-Gee, aren't you a man? You have to go back home and do not allow it."

In same-sex IPV concealment is increased further because, in addition to what we have discussed earlier, homophobia and the lack of legal recognition of their relationships must be confronted. Also, their relationships are stereotyped as "passionate" and thereby are expected to be impulsive and to use unbridled violence. Thus, their complaints would have to remove more obstacles than in similar cases with heterosexual people, and this further hinders possible action by the authorities.

Ignorance of the process of the system of complaints corresponds to the absence of sufficient information to enable maltreated people to report abuse. We found as causes of IPV concealment several issues related to the lack of knowledge of where to report, what to do, what is the process to be followed to make a complaint, what are the implications, how long does it takes, what costs are involved, what documents are requested, etc. Clearly, such uncertainties with the IPV denouncement process inhibit people from seeking help.

\subsection{Idyllic love}

Idyllic love is associated with a sense of un-conditionality and the idea of support in adversity. Clearly, permanence is seen as a desirable value in intimate relationships. Regardless of sex and sexual orientation, we found that people frequently keep in secrecy their IPV because denouncing it is against this ideal. They were impelled to be supportive so that their relationship would endure, to the point of interpreting it as their responsibility. By succeeding in the permanence of their relationship, they neglect their own needs and well-being. Hence, IPV concealment becomes interwoven with these values of un-conditionality and support in adversity, which enables the permanence of a relationship (e.g. Ana, a 57 year-old heterosexual woman, after her 20-year IPV experience): "I accepted it because I wanted a happy family, you know, one with a nice husband and wife, good children, and a lovely house, but it was a lie." 
Furthermore, love attains a transforming magical power with which the couple will change mistreatment to caring behavior. The complaint becomes meaningless, since people believe that love has the power to transform violence. Hence, if violence is present, then a challenge exists to increase this transforming power of love. For instance, it is in the name of love that people tend to justify the violence of the couple (e.g. "He shouts because he is tired, or because he has a lot of work".)

\subsection{Social stigma of violence}

Partly because violence has a certain degree of social stigma, IPV tends to be hidden. Violence has social disapproval, both to exercise it and to receive it. It becomes a factor that restricts the search for help to escape violence. Some people fear rejection from family, friends and community, after suffering IPV. It is even associated with shame: the inability to choose the right partner and not being able to handle situations that lead to violence.

"He hit me several times, and I never had the courage to sue him. First, to avoid complaints from my family. I thought 'if I sue him, what shame!', because my family will say-look at you, why did you live with that man? I did not want to let them have pity on me": Juanita (a separated, 45 year-old heterosexual woman).

\subsection{Youth}

The young have emerged as a factor in IPV concealment. Reasons for concealment are inexperience and lack of resources (e.g. economic, labor, cognitive, previous experiences of peaceful conflict management) that are related to youth.

"I was also very young. I was 17 years old. I was overwhelmed; it was like the world was closed to me. I thought, 'it is better not to tell, otherwise it will get worse', or because I loved him, I had to endure it. I just had to bear it": Juanita. Not surprisingly, people used to argue that both youth and idyllic love are commonly present in IPV concealment.

\subsection{Caring for children and relationships}

People hide IPV when it is decided that to denounce it would be harmful to the children and/or when there is fear of losing other relationships. One of the main concerns in heterosexual couples, especially women, is to keep the family with maternal and paternal figures, as a way to protect the proper development of the offspring. IPV concealment took place if it was believed that the complaint would be detrimental to the stability of the children.

Another factor to silence IPV was the fear of losing the relationship with family and friends. Sometimes a maltreated person estimated that upon the discovery of IPV some friends and relatives will unite to protect the partner, resulting in a personal loss and further isolation. Hence, when abused people value their bond with relatives and friends they might prefer to conceal IPV. Even political family can be important when making the decision: 
"I used to get along with the family of my husband, with my mother in law and my brothers in law. I thought, 'If I put my husband into jail, I'll end up so badly with all of his family members": Mary (a divorced 45 year-old heterosexual woman).

In the case of same-sex couples, participants tended to hide their relationships from their families, because they feared rejection and misunderstanding. This fact imposes a double secrecy when relationships turn violent, and leaves people in a more vulnerable situation.

"I was in a restaurant with Ana, my girlfriend. We were having a fight. Then my father passed by in that mall, and stopped to say hello. I took the excuse to go to the restroom because I was so afraid that Ana would tell my father about us. He wasn't aware of my sexual-orientation [...] in the restroom she wanted to hit $m e$ ": Celia (a 25 year-old lesbian woman).

\subsection{Isolation}

IPV concealment is compounded by social isolation. When a person lacks a strong and reachable support network, a state of vulnerability is produced that depletes resources for complaints. This is common with people who move to another city, live in isolated communities, or have poor social interactions. Another factor with isolation is when the couple's relationship exists in secrecy, as in the case of same-sex couples where families may be unaware of their homosexuality.

\section{Discussion}

Concealment of IPV has been characterized from the experiences of men and women in the HGLB communities. Findings from these studies reveal that the concealment of IPV is linked to social imaginary (Castoriadis 1986), where norms, values, and beliefs supported by gender stereotypes interact with social practices. For instance, one form of inefficiency in the application of justice is linked to legal services workers who reinforce gender stereotypes when abused people make denunciations. Also, IPV concealment can be influenced by the beliefs of idyllic love, and the stigmatization or normalization of violence. In addition, concealment of IPV becomes conditioned by youth and the consequences that denunciation of violence can have. The abused person assesses the impact that the complaint could have on their children and the isolation that could bring the withdrawal of friends and family from friendly relationships with the couple. Thus, denunciation of women and men is discouraged at different levels, for example, individually or with couples, as in a community setting.

Baron and Byrne (2005) established that stereotypes are cognitive frameworks that influence information processing. This study shows empirically that gender stereotypes have implications on the practical life of couples. Social representations (Jodelet 1984) that are generated with stereotypes determine how people feel, 
think, and interact in their relationships. We found that these constructions transcend sexual orientation, and make clear its inter-subjective component.

Melton and Sillito (2012) noted that the manner in which primary agents of the judicial system respond to IPV can determine whether the person who experienced violence will take legal actions or not. Our findings with IPV concealment, while confirming this, qualitatively expand specific factors of negligence of the authorities that lead to IPV. Neglect minimizes the problem, its normalization, its naturalization, or renders it a private matter. IPV is hidden because a complaint has its own risks. We found that a complaint is discouraged when people doubt the effectiveness of the system. The abused person may be at greater risk if the authority does not comply with the request or fails to take sufficient precautionary measures to protect the abused person properly. Hence, IPV concealment is compounded by the decisions that people make of their possible success.

Frías (2013) reported that $11.43 \%$ of women did not report IPV, in order to prevent disclosure to their families. Our study confirms that this reason for concealment is not only true for heterosexual women, but is also true for all HGLB men and women. However, it must be mentioned that the motivations to hide have their particularities dependent on gender and sexual orientation. Heterosexual couples are heavily influenced by stereotypes and gender roles. In the case of same-sex couples, homophobia is also a factor which results in double secrecy: that of sexual orientation and also that of IPV itself.

Other studies show that personal relationships are an important factor in decision-making about the complaint. It has been reported that when people know those who commit crimes (e.g. friends), they are less likely to report them (Nicksa 2014). In the specific case of IPV, it has been found that the decision of heterosexual women to seek help (Meyer 2010, 2012), or the withdrawal of protection orders (Malecha et al. 2003) are concerns when the welfare of children are considered. Our study confirms that the IPV experienced by heterosexual women is hidden if it is believed that the complaint could upset the stability of children. However, we also found that another factor is to guarantee the bonds with one's own family, and with families and friendships that have been developed together as a couple. When these relationships are valued by the abused person, they may become a barrier to the complaint, regardless of gender and sexual orientation. We found that people consider their losses and how much she or he will be isolated if friends and family become allied with the couple to protect her or him. Thus, these results show how people broadly evaluate the possibilities of the complaint and its consequences. These factors should be considered by professionals who are involved in IPV treatment.

Agoff et al. (2006) found that women under 35 years of age are more tolerant than older women, suggesting that many years of abuse do not favor its acceptance. This study empirically confirms these findings, and supplements them by establishing that the factor of youth is affected by the adjustment to the beliefs of idyllic love, and that this applies to HGLB. Lack of knowledge, inexperience of youth, and the beliefs related to un-conditionality, permanence and support in 
adversity, come together. These results suggest that preventive interventions should be encouraged from an early age, including elements of socio-cognitive development to promote the culture of IPV complaint, from the comprehensive perspective of both sexes and sexual orientations.

Frías (2013) suggested that isolation is a strategy to hide the exercise of power that violent people use. We have found that IPV concealment is indeed associated with higher states of isolation. This isolation increases when people move to new towns, live in isolated communities with poor communication, have no close friends, or when the relationship is held in secrecy (as in the case of same-sex couples where families are unaware of their homosexuality).

These results are part of a qualitative study from the urban area of Querétaro, Mexico and may not be expanded to other regions and cultures. It is recommended that further research confirm these findings in rural areas and other regions. It is necessary to do larger studies with representative samples.

In conclusion, it has been shown that the phenomenon of IPV concealment, in men and women of HGBL communities, is conditioned by models that are reproduced at different levels: individually, in their relationships and in social structures. These results highlight the importance of expanding the IPV studies to include HGBL women and men. It is necessary to abandon the reductionist view of heterocentrism to better understand social life in its complexity and to promote fair and appropriate social policies.

\title{
Acknowledgement
}

This research was supported, in part, by a scholarship from CONACYT, Mexico. The authors thank the participants for their time and generosity and Dr. Paul Riley, formerly a United States Peace Corps volunteer in Mexico, for his help in the revision of the manuscript.

\author{
Address: \\ M. E. Meza-de-Luna \\ Facultad de Ciencias Políticas y Sociales \\ Circuito Universitario Las Campanas \\ Centro, C.P. 76000 Querétaro, México \\ Tel.: + 52.442.192.12.00 ext. 5451 \\ E-mail:mezamariel@gmail.com,PrevenirAbuso@gmail.com
}

\section{References}

Agoff, Carolina, Ari Rajsbaum, and Cristina Herrera (2006) "Perspectivas de las mujeres maltratadas sobre la violencia de pareja en México.” Salud Pública de México 48, 2, 307-314.

APA (2010) Publication manual of the american psychological association. 6th ed. Washington, DC: American Psychological Association. 
Atlas.ti (2007) “The knowledge workbench (Version WIN 5.0).(Build 60). [Software]. Berlín: Scientific Software Development."

Baron, Robert and Donn Byrne (2005) Psicología social. Edited by J. V. Prestana, A. Castrechini, and L. Fernández. Translated by J. V. Prestana, A. Castrechini, and L. Fernández. 10. ed. Madrid: Pearson Education and Prentice Hall.

Burgess-Proctor, Amanda (2012) "Pathways of victimization and resistance: toward a feminist theory of battered women's help seeking". Justice Quarterly 29. doi: 10.1080/07418825.2011.553727. Available online at $<\mathrm{http} / / / \mathrm{www}$.tandfonline.com/doi/abs/10.1080/07418825.2011.553727>. Accessed on 01.08.2014.

Calzada-Rovirosa, José (2012) "Tercer informe de gobierno". Querétaro, México: Poder Ejecutivo del Estado de Querétaro. Available online at <http://dialogoqueretano.com.mx/versionestenografica-tercer-informe-de-gobierno-de-jose-calzada-rovirosa/ $>$. Accessed on 01.08.2014.

Cantera-Espinosa, Leonor María (2009) "La fotointervención como herramienta docente." Revista de Enseñanza de La Psicología 1, 18-30.

Castoriadis, Cornelius (1986) "El campo de lo social histórico." Estudios: Filosofia, Historia, Letras. Available online at <http://www.franjamoradapsico.com.ar/home/descargas/resumenes/ 2a\%C3\%B1o/DHEP I/Castoriadis, C - El campo de lo social hist\%C3\%B3rico.pdf $>$. Accessed on 01.08.2014.

Charmaz, Kathy (2008) Constructing ground theory: a practical guide through qualitative analysis. Londres: Sage.

Coker, Ann L, Paige H. Smith, Daniel J. Whitaker, Brenda Le, Timothy N. Crawford, and Vicki C. Flerx (2012) "Effect of an in-clinic IPV advocate intervention to increase help seeking, reduce violence, and improve well-being". Violence against Women 18,1, 118-31. doi:10.1177/1077801212437908. Available online at <http://www.ncbi.nlm.nih.gov /pubmed/22411302>. Accessed on 01.08.2014.

Facultad de Ciencias Políticas y Sociales (2012) "Plan de estudios de la especialidad en familias y prevención de la violencia”. Querétaro, México.

Frías, Sonia M. (2013) "Strategies and help-seeking behavior among mexican women experiencing partner violence." Violence against Women 19, 1, 24-49. doi: 10.1177/1077801212475334. Available online at <http://www.ncbi.nlm.nih.gov/pubmed/23404245>. Accessed on 01.08 .2014

Hamel, John (2007) "Domestic violence: a gender-inclusive conception". In A handbook of genderinclusive theory and treatment: family interventions in domestic violence, 3-26. John Hamel y Tonia L. Nicholls, eds. New York: Springer Publisher.

Instituto Municipal de Equidad y Género (2008) "Diagnóstico situacional de las mujeres en el municipio de Querétaro, Querétaro". Querétaro.

Instituto Nacional de Estadística y Geografía (2008) "Las mujeres en Querétaro. Estadísticas sobre desigualdad de género y violencia contra las mujeres". Querétaro. Available online at $<$ http://www.diputados.gob.mx/documentos/Congreso Nacional_Legislativo/delitos estados /La_mujer_qro.pdf $>$. Accessed on 01.08.2014.

Instituto Nacional de Estadística y Geografía (2013) "Anuario estadístico y geográfico de Querétaro". México. Available online at $<\mathrm{http}$ ://www.inegi.org.mx/prod serv/contenidos/ espanol/bvinegi/productos/integracion/pais/anuario_multi/2013/qro/AEyGQRO13.pdf>. Accessed on 01.08.2014.

Jodelet, Dennise (1984) La representación social: fenómenos, conceptos y teorías. Psicología Social II. Barcelona, España: Paidós.

Johnson, Michael P. (1995) "Patriarchal terrorism and common couple violence: two forms of violence against women". Journal of Marriage and the Family 57, 2, 283-294.

Leone, Janel M., Michael P. Johnson, and Catherine L. Cohan (2007) "Victim help seeking: differences between intimate terrorism and situational couple violence". Family Relations 56, $5,427-439$

Logan, T. K, Lisa Shannon, Robert Walker, and Teri Marie Faragher (2006) "Protective orders: questions and conundrums". Trauma, Violence \& Abuse 7, 3, 175-205. doi: 
10.1177/1524838006288930. Available online at $<$ http://www.ncbi.nlm.nih.gov/pubmed/ 16785286>. Accessed on 01.08.2014.

Malecha, Ann, Judith McFarlane, Julia Gist, Kathy Watson, Elizabeth Batten, Iva Hall, and Sheila Smith (2003) "Applying for and dropping a protection order: a study with 150 women". Criminal Justice Policy Review 14, 4, 486-504. doi: 10.1177/0887403403255496. Available online at $<$ http://cjp.sagepub.com/ cgi/doi/10.1177/0887403403255496>. Accessed on 01.08.2014.

Melton, Heather C., and Carrie Lefeve Sillito (2012) "The role of gender in officially reported intimate partner abuse". Journal of Interpersonal Violence 27, 6, 109-111. doi: 10.1177/ 0886260511424498. http://www.ncbi.nlm.nih.gov/pubmed/22203618>. Accessed on 01.08.2014.

Mendizábal, Nora (2006) "Los componentes del diseño flexible en la investigación cualitativa". In Estrategias de investigación cualitativa, 65-105. Irene Vasilachis de Gialdino, ed. (coord.) Barcelona, España: Gedisa.

Meyer, Silke (2010) "Responding to intimate partner violence victimisation: effective options for help-seeking". Centre of Excellence in Policing. Available online at $<\mathrm{http}: / / \mathrm{www}$.aic.gov.au/ publications/current series/tandi/381-400/tandi389/view paper.html $>$. Accessed on 01.08 .2014$.

Meyer, Silke (2012) "Why women stay: a theoretical examination of rational choice and moral reasoning in the context of intimate partner violence". Australian \& New Zealand Journal of Criminology 45, 2, 179-193. doi: 10.1177/0004865812443677. Available online at $<\mathrm{http}: / /$ anj.sagepub.com/lookup/doi/10.1177/ 0004865812443677>. Accessed on 01.08.2014.

Nicksa, Sarah C. (2014) “Bystander's willingness to report theft, physical assault, and sexual assault: the impact of gender, anonymity, and relationship with the offender". Journal of Interpersonal Violence 29, 2, 217-36. doi: 10.1177/ 0886260513505146. Available online at $<$ http://www.ncbi.nlm.nih.gov/pubmed/ 24142441>. Accessed on 01.08.2014.

Oliver, Paul (2008) Writing your thesis. 2nd ed. United Kigdom: Sage Study Skills.

Ortega-Ceballos, Paola Adanari, Jyoti Mudgal, Yvonne Flores, Leonor Rivera-Rivera, Juan Carlos Díaz-Montiel, and Jorge Salmerón (2007) "Determinantes de violencia de pareja en Trabajadoras Del IMSS, Morelos.” Salud Pública de México 49, 5, 357-366.

Palacios-Sierra, Patricia (2007) "El trabajo femenino en Querétaro: un estudio de familias con perspectiva de género". In Globalización y región. Querétaro y el debate actual, 97-157. Alfonso Serna-Jiménez and Ramón Del-Llano-Ibáñez, eds. México.

Sánchez-Jimenez, Bernarda, María Hernández-Trejo, and Teresa Lartigue-Becerra (2008) "Violencia conyugal y depresión durante el embarazo." Salud Pública de México 50, 5, 353-354.

Sanz, Fina (2008) La Fotobiografia. imágenes e historias del pasado para vivir con plenitud el presente. Barcelona: Kairós.

Sontag, Susan (2005) Sobre la fotografia. Madrid: Alfaguara- Santillana.

Straus, Murray A. (2006) "Future research on gender symmetry in physical assaults on partners". Violence against Women 12, 11, 1086-1097.

Strauss, Anselm, and Juliet Corbin (2002) Bases de la investigación cualitativa: técnicas y procedimientos para desarrollar la teoría fundamentada. 1. ed. Medellín, Colombia: Universidad de Antioquia.

Thornton, Abigail J. V., Nicola Graham-Kevan, and John Archer (2012) "Prevalence of women's violent and nonviolent offending behavior: a comparison of self-reports, victims' reports, and third-party reports". Journal of Interpersonal Violence 27, 8, 1399-1427. doi: 10.1177/0886260511425789. Available online at <http:// www.ncbi.nlm.nih.gov/pubmed/ 22547574>. Accessed on 01.08.2014.

United Nations (n.d.) "Households and families". United Nations. Available online at $<$ http://unstats.un.org/unsd/demographic/sconcerns/fam/fammethods.htm\#B $>$. Accessed on 01.08.2014.

Willson, Pam, Judith McFarlane, Dorothy Lemmey, and Ann Malecha (2001) "Referring abused women: does police assistance decrease abuse?”. Clinical Nursing Research 10,1, 69-81. 
